\title{
Identifying factors associated with the uptake of prevention of mother to child HIV transmission programme in Tigray region, Ethiopia: a multilevel modeling approach
}

Wondwossen Lerebo ${ }^{1,2^{*}}$, Steven Callens ${ }^{3}$, Debra Jackson ${ }^{1}$, Christina Zarowsky ${ }^{1}$ and Marleen Temmerman ${ }^{4}$

\begin{abstract}
Background: Prevention of mother to child HIV transmission (PMTCT) remains a challenge in low and middle-income countries. Determinants of utilization occur - and often interact - at both individual and community levels, but most studies do not address how determinants interact across levels. Multilevel models allow for the importance of both groups and individuals in understanding health outcomes and provide one way to link the traditionally distinct ecological- and individual-level studies. This study examined individual and community level determinants of mother and child receiving PMTCT services in Tigray region, Ethiopia.
\end{abstract}

Methods: A multistage probability sampling method was used for this 2011 cross-sectional study of 220 HIV positive post-partum women attending child immunization services at 50 health facilities in 46 districts. In view of the nested nature of the data, we used multilevel modeling methods and assessed macro level random effects.

Results: Seventy nine percent of mothers and $55.7 \%$ of their children had received PMTCT services. Multivariate multilevel modeling found that mothers who delivered at a health facility were 18 times (AOR $=18.21 ; 95 \% \mathrm{Cl}$ $4.37,75.91)$ and children born at a health facility were 5 times ( $\mathrm{AOR}=4.77 ; 95 \% \mathrm{Cl} 1.21,18.83$ ) more likely to receive PMTCT services, compared to mothers delivering at home. For every addition of one nurse per 1500 people, the likelihood of getting PMTCT services for a mother increases by 7.22 fold (AOR $=7.22 ; 95 \% \mathrm{Cl} 1.02,51.26$ ), when other individual and community level factors were controlled simultaneously. In addition, district-level variation was low for mothers receiving PMTCT services ( $0.6 \%$ between districts) but higher for children (27.2\% variation between districts).

Conclusions: This study, using a multilevel modeling approach, was able to identify factors operating at both individual and community levels that affect mothers and children getting PMTCT services. This may allow differentiating and accentuating approaches for different settings in Ethiopia. Increasing health facility delivery and HCT coverage could increase mother-child pairs who are getting PMTCT. Reducing the distance to health facility and increasing the number of nurses and laboratory technicians are also important variables to be considered by the government.

\footnotetext{
* Correspondence: darfiroerjabo@yahoo.com

${ }^{1}$ School of Public Health, University of the Western Cape, Cape town, South

Africa

${ }^{2}$ College of Health Science, Mekele University, Mekele, Ethiopia

Full list of author information is available at the end of the article
} 


\section{Background}

With an estimated 1.1 million people living with HIV, Ethiopia has one of the largest populations of HIV infected people in the world [1]. The Government of Ethiopia has started integrating services such as prevention of mother to child HIV transmission (PMTCT) and HIV counseling and testing (HCT) within family planning and maternal, newborn and child health services.

Despite the overall increase in PMTCT coverage and uptake in developing countries, it remains low and unevenly distributed. Access to PMTCT services remains a challenge in the fight against HIV/AIDS and for reaching the Millennium Development Goals (MDGs) in Ethiopia. Mother to child HIV transmission (MTCT) remains high: UNAIDS estimated that almost 330,000 children were infected, and 230,000 children under fourteen years of age died of HIV in 2011 [2]. Around 90 percent of child infections occur in sub-Saharan Africa [2], and Ethiopia is not an exception.

Interventions exist that can reduce MTCT from 20\% $45 \%$ to less than $1 \%-2 \%$ [3-5]. Vertical transmission of HIV in low- and middle-income countries has declined to less than $5 \%$ in the best-case scenarios after the introduction PMTCT strategies [6-8], and in wealthy countries, transmission rates are below $2 \%[9,10]$.

Although Ethiopia has made progress in the provision of services to reduce MTCT by increasing the proportion of women getting tested and knowing their results through expanding rapid testing to many PMTCT sites, national ANC coverage is only $66.3 \%$, and coverage of skilled birth at a health institution is a mere $24.9 \%$. HIV testing, antenatal care and skilled birth attendants influence the utilization of PMTCT [11].

Ethiopia is one of the six countries that account for $50 \%$ of under- 5 child deaths worldwide, with approximately 350,000 Ethiopian children dying each year [12]. Eleven percent of child deaths result from HIV/AIDS [13]. To avert these deaths, detection of maternal infection early in pregnancy through HCT and access to antiretroviral prophylaxis is crucial. Generally, the uptake of these interventions remains low, primarily due to low ANC uptake and poor antenatal HIV testing rates $[14,15]$.

In Ethiopia, a total of 1,023 health facilities were providing PMTCT services at the end of 2009. More than 616,763 pregnant women had at least one ANC visit in 2009 , and 417,841 women underwent HCT, of whom 10,267 (2.4\%) tested positive. Of all the pregnant women diagnosed with HIV, only 6,466 (63\%) received antiretroviral prophylaxis (ARV/NVP) and only 5,025 infants received PMTCT prophylaxis in the same year. Of the total estimated 84,189 HIV-positive pregnant women in 2009 only $8 \%$ received ARV/NVP during childbirth [11].

Several papers have studied the determinants of getting PMTCT services. Cultural and social barriers that may prevent receipt of PMTCT services have not received adequate attention [16]. In general, challenges cited include limited screening for HIV in children, lack of affordable, simple diagnostic testing technologies, lack of human capacity, insufficient advocacy and poor understanding that ART is efficacious in children [15]. Evidence also suggests that factors operate at both the micro and macro level in getting PMTCT services. Micro-level factors include health seeking behaviour [17], adherence [18,19], home delivery [14], non-attendance of ANC [14], lack of knowledge [20], stigma [20], discrimination [20], trust in the hospital [21], while the macro level includes factors such as underlying inequities in healthcare quality [22], health services [17], health policy [17], distance and transport cost [21].

A drawback of these studies has been the use of single level analytical techniques that ignore clustering and the hierarchical structure of data for individuals living in different households, neighborhoods, cities, and provinces. Multilevel modeling can account for factors at individual and community levels simultaneously and provide a more robust understanding of the factors associated with receiving PMTCT services [23].

The main reason to apply multilevel modeling is that many kinds of data, including observational data collected in the human and biological sciences have a hierarchical or clustered structure [24]. Individuals interact with the social contexts to which they belong, meaning that individual persons are influenced by their social groups or contexts, and that the properties of those groups are in turn influenced by the individuals who make up that group. Generally, the individuals and the social groups are conceptualized as a hierarchical system (see Figure 1), with individuals and groups defined at separate levels of this hierarchy. Naturally, such systems can be observed at different hierarchical levels, and variables may be defined at each level [25]. Because of growing statistical technology and increasing interest in societal influences on individual health status, group level and individual level factors in regression models have prompted interest in contextual research in epidemiology [26]. The statistical issues involved in multilevel studies have been well described, and hierarchical regression analysis is becoming widely accepted as the appropriate tool for examining group level effects on individual health [27]. However, as far as we can determine, this variation in health has received little attention in public health until recently and is almost invisible in African studies on receiving PMTCT services.

By explicitly acknowledging the existence of groups, modeling group-to-group variation simultaneously with individual-to-individual variation, and including grouplevel properties with individual-level variables in the analyses, multilevel models allow for the importance of both groups and individuals in understanding health outcomes. They provide one way to link the traditionally 


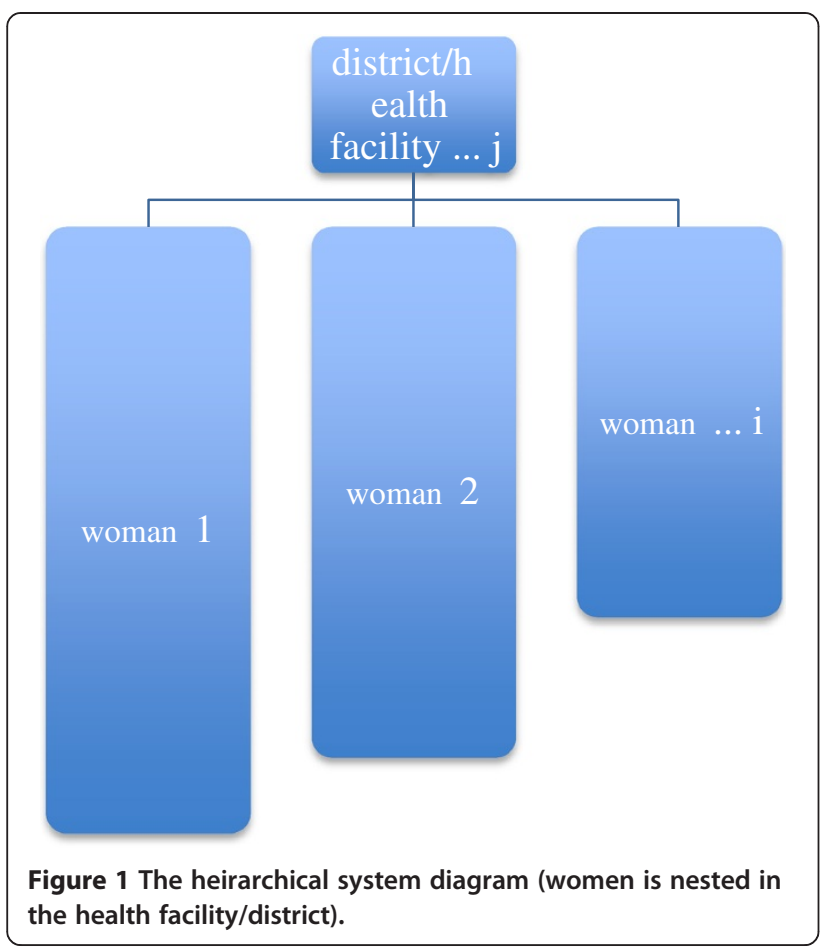

distinct ecological- and individual-level studies and to overcome the limitations inherent in focusing only at one level. Like other statistical methods, multilevel analysis helps to describe, summarize, and quantify patterns present in the data [23].

Although several individual characteristics have been associated with getting PMTCT services (e.g., age, education), associations with contextual characteristics, such as nurse load, PHC per population (see Figure 2), have largely been understudied. Several theoretical frameworks [28,29] have, however, stressed that the immediate environment (e.g., home or community context) may influence individuals'

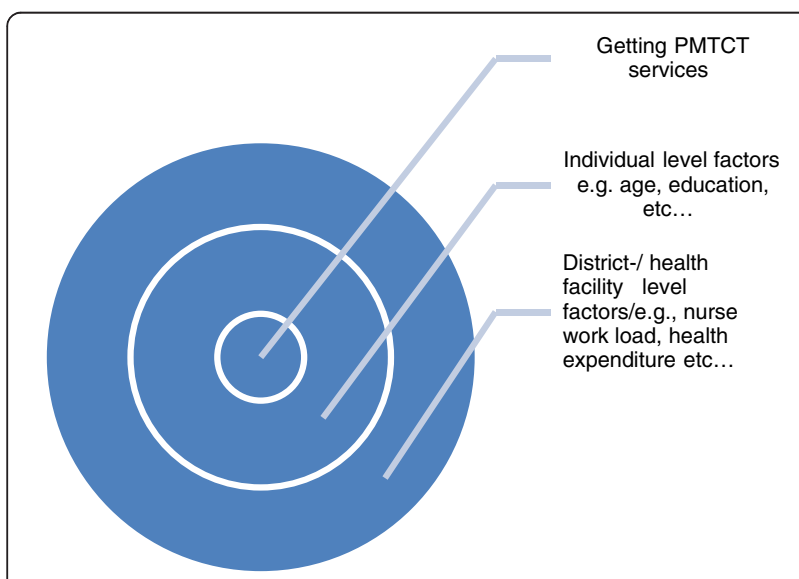

Figure 2 Conceptual model of macro- and micro-level factors affecting getting PMTCT services. health behaviour. Nevertheless, most studies on PMTCT have applied single-level analytic techniques, ignoring the social context within which individuals live [30-32]. This study explicitly examined both individual and contextual level correlates of receiving PMTCT services, by implementing a multilevel methodological approach.

The research questions that this study explored are the following: What are the individual and contextual factors that affect receipt of PMTCT services? Which determinants (community or individual level) are influential for receipt of PMTCT services inter and intra districts (woredas) in Tigray region Ethiopia?

\section{Methods}

The economy of Ethiopia is dependent on agriculture, contributing $47 \%$ to the Gross National Product (GNP) and accounting for more than $80 \%$ of exports, as well as providing employment for $85 \%$ of the population [33]. The Tigray Region has a total population of more than 4.3 million; urban inhabitants make up $19.5 \%$ of the population [34]. The estimated population density is 86.15 people per square kilometre. The region has 1 million households, with an average of 4.4 persons to a household, with urban households having on average 3.4 and rural households 4.6 people.

Only half of the population has access to health services. The ANC coverage in Tigray region in 2009 was $73.0 \%$, $43 \%$ of mothers utilizing ANC were tested for HIV, and of these, 3.1\% tested positive [35]. Only half of HIV positive pregnant women and $38 \%$ of babies born to HIV positive mothers were given single dose nevirapine (sdNVP) or combination antiretroviral treatment (cART).

From May 05 to July 15, 2011 a health facility based cross-sectional study was conducted in Tigray, Ethiopia. The participants were selected by using a multistage sampling. Forty six districts, comprising 13 hospitals and 208 health centers were determined by the Tigray region Bureau of Health [35]. One health center from each district randomly and all available hospitals were chosen. Thirty to 36 post-partum women were purposively selected from each health facility. The managers of all of the selected health facilities and districts were also interviewed.

All participants were interviewed face to face by a trained nurse using structured questionnaire to collect information on demographic, socio-economic characteristics and on women's maternal healthcare, for instance, prenatal care, delivery and postnatal care related to PMTCT. Informed consent was obtained from each participant at the start of the survey. The study was approved by the ethics committee of University of the Western Cape, and Tigray region Health Bureau.

"Getting PMTCT service" during the last pregnancy and delivery was used as the principal outcome indicator in the analysis of the demographic and socio-economic 
determinants at the individual and community level. This indicator, coded 1 for "yes" or 0 for "no", was defined in accordance with the Ministry of Health PMTCT guidelines as follows: the mother was asked if she received antiretroviral medication, before, after or/and at the time of labour depending on her clinical stage, and whether the child received prophylaxis at the time of birth or/and after birth depending on the mother's clinical stage.

A two level logistic regression model was used to assess the explanatory effects of the independent variables on getting PMTCT services by considering the hierarchical structure of the study sample. The first level represents the individual and the second level is the district/ community. The community level covariate was the geographical demarcation of the districts.

Individual level covariates comprised age group $(\leq 24$, $25-34$, or $\geq 35$ ) years; education (categorized as none, primary, or secondary/higher); number of pregnancy $(\leq 2$ or $\geq 3$ ); place of delivery (home or health facility); ever stigmatized (yes or no); ever discriminated (yes or no); planned pregnancy (yes or no); any $\mathrm{CD}_{4}$ count done (yes or no); time of HIV status knowledge (before being pregnant, during pregnancy, at the time of delivery, or after giving birth); HIV status disclosure to the spouse (yes or no); who attended the birth of child (traditional birth attended, doctor, or nurse/mid-wife/other); and socio-economic status (SES) quintile $\left(1^{\text {st }}\right.$ quintile (poorest), $2^{\text {nd }}$ quintile, $3^{\text {rd }}$ quintile, $4^{\text {th }}$ quintile, or $5^{\text {th }}$ quintile (wealthiest)). The quintile combined information on a set of household assets and living conditions: the household income, employment status, main source of water, type of toilet, main fuel used for cooking, and main material the house built.

Data on the community level variables included in the model were obtained from the questionnaires for mothers health facility and district managers and complemented by official data from secondary source [35]. Place of residence grouped as urban, rural; proportion of women with no education in the district grouped as $<30 \%, 30-50 \%,>50 \%$; proximity grouped as $<1 \mathrm{~km}, 1-5 \mathrm{kms},>5 \mathrm{kms}$; nurse workload defined as $\leq 1500$, $>1500$ people per nurse; proportion of poor and poorest household in the district grouped as $<30 \%, 30-60 \%$, $>60 \%$; people per health worker defined as $\leq 500,>500$; people per health facility defined as $\leq 25000,>25000$; lab technician workload defined as $\leq 3100$, $>3100$ people; and people per HCT site grouped as $\leq 25000,>25000$.

The community level random effects were estimated, using xtmelogit function, at a 2-level multilevel model as shown:

$$
\log \left(\frac{\pi_{i j}}{1-\pi_{i j}}\right)=\beta_{0}+\beta_{1} X_{i j}+u_{0 j}
$$

With $\beta_{0}$ as the intercept and the slope $\beta_{1}$, defined as the expected change in getting PMTCT service. A set of intercepts was estimated for the community level, where ${ }^{\pi} \mathrm{ij}$ is the probability of utilizing HCT for a pregnant woman $\mathrm{i}$, in a district $\mathrm{j}$, and $\beta 0 \mathrm{j}$ is a parameter associated with the fixed part of the model. Therefore, for every one unit increase in $\mathrm{X}$ (a set of predictor variables) there is a corresponding effect on the probability mother or child getting PMTCT service. By assuming that each community has a different intercept $\beta_{0 j}$ and a different slope $\beta_{1 j}$ the clustered data structure and the within and between community variations is now taken into account. To capture the extent by which choice of different option of getting PMTCT service, which are contrast specific, varies randomly at the individual level, the results of random effects (measures of variation) are presented as variance partition coefficient (VPC):

$$
v p c=\frac{\sigma_{u 0}^{2}}{\sigma_{u o}^{2}+\frac{\pi^{2}}{3}}
$$

Where, $\pi^{2} / 3$ denotes the variance between mother or child from the same district (individual level) and $\sigma 2 u 0$ is the variance between districts (community level variance).

Data analyses were conducted using Stata 11 (Stata Corp. Inc., TX, USA). The statistical significance of the explanatory variables was estimated using Wald statistics, with all results at $<5 \%$ alpha level considered significant. The results of the fixed (measure of association) effects were presented as odds ratio (OR) at their 95\% confidence intervals (95\% CIs).

As this study used several explanatory variables that might be correlated to each other (such as mother's education, father's education and household wealth index), the multicollinearity assessment was conducted using the means of variance inflation factors and it is small (1.22) indicated the absence of any significant collinearity between explanatory variables in the regression model.

\section{Results}

Among the $220 \mathrm{HIV}$ positive mothers, 95.4\% have provided information about PMTCT. Of these, 79\% of mothers and $55.7 \%$ of children reported receiving PMTCT services (Table 1).

\section{Multilevel analysis \\ Crude multilevel modeling result}

In crude multilevel modeling the odds of getting PMTCT service were 14 times $(\mathrm{OR}=13.99$; 95\% CI 4.94,39.60) higher for a mother delivering at a health facility, and a child born at a health facility was 7 times $(\mathrm{OR}=6.93$; 95\% CI 2.27,21.14) more likely to get PMTCT services than a mother delivering and child born at home, respectively. The bivariate multilevel modeling showed that having a CD4 count significantly increased the odds of receiving PMTCT services for both mother $(\mathrm{OR}=8.30$; 
Table 1 Background individual and community-level characteristics of post-partum women who were attending health facility for the child immunization and mother and child PMTCT service in Tigray region Ethiopia

\begin{tabular}{llll}
\hline Variables & n & $\begin{array}{l}\text { Mother } \\
\text { PMTCT\% }\end{array}$ & PMild \\
PMTCT\%
\end{tabular}

Age group (years)

$\begin{array}{llll}\leq 24 & 35 & 71,4 & 68,6 \\ 25-34 & 140 & 81,4 & 50,7 \\ \geq 34 & 33 & 75,8 & 63,6\end{array}$

Mother education

$\begin{array}{llll}\text { No education } & 90 & 77,8 & 61,1 \\ \text { Primary } & 81 & 76,5 & 53,1 \\ \text { Secondary/Higher } & 38 & 89,5 & 47,4\end{array}$

Father education

No education

Primary

Secondary/Higher

Religion

Orthodox
Non Orthodox

Household size

$\leq 3$

$>3$

$56 \quad 75,0 \quad 57$,

$81 \quad 82,7 \quad 61,7$

$66 \quad 80,3 \quad 47,0$

$191 \quad 78,0 \quad 55,5$

$19 \quad 89,5 \quad 57,9$

Number of pregnancy

$$
\begin{aligned}
& \leq 2 \text { times } \\
& >2 \text { times }
\end{aligned}
$$

Age of first pregnancy

$$
\begin{aligned}
& \leq 25 \text { years } \\
& >25 \text { years }
\end{aligned}
$$$$
15381,0 \quad 59,5
$$$$
23 \quad 69,6 \quad 34,8
$$

Utilized ANC

$$
\begin{aligned}
& \text { No } \\
& \text { Yes }
\end{aligned}
$$

Where was the child born?

$$
\begin{aligned}
& \text { Home } \\
& \text { Health facility }
\end{aligned}
$$$$
102 \quad 78,4 \quad 55,9
$$$$
93 \quad 78,5 \quad 54,8
$$$$
167 \quad 78,4 \quad 55,1
$$$$
38 \quad 84,2 \quad 60,5
$$

Have you ever stigmatized?

$$
\text { Yes }
$$$$
\text { No }
$$

Have you ever discriminated?

$$
\begin{aligned}
& \text { Yes } \\
& \text { No }
\end{aligned}
$$

Confidentiality with health workers

$$
\begin{aligned}
& \text { No } \\
& \text { Yes }
\end{aligned}
$$

\section{No}$$
3470,6
$$$$
41,2
$$$$
17580,6
$$

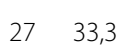

25,9

18286,3

$$
\begin{array}{lll}
113 & 80,5 & 54,9 \\
97 & 77,3 & 56,7
\end{array}
$$

$$
\begin{array}{lll}
81 \quad 77,8 \quad 59,3
\end{array}
$$$$
126 \quad 81,8 \quad 54,8
$$

$128 \quad 82,8 \quad 55,5$

$81 \quad 74,1 \quad 56,8$
Table 1 Background individual and community-level characteristics of post-partum women who were attending health facility for the child immunization and mother and child PMTCT service in Tigray region Ethiopia (Continued)

\begin{tabular}{llll}
\hline Knowledge level of HIV & & & \\
Poor & 98 & 78,6 & 49,0 \\
Good & 112 & 79,5 & 61,6 \\
Planned pregnancy & & & \\
No & 72 & 81,9 & 65,3 \\
Yes & 132 & 78,0 & 50,8
\end{tabular}

Discussed the best way to feed with anyone

$\begin{array}{llll}\text { No } & 36 & 72,2 & 55,6 \\ \text { Yes } & 170 & 80,6 & 56,5\end{array}$

Have you had CD4 count?

$\begin{array}{lccc}\text { Yes } & 183 & 84,7 & 59,0 \\ \text { No } & 25 & 40,0 & 36,0\end{array}$

Father of child tested for HIV

$\begin{array}{llll}\text { No/Don't Know } & 69 & 75,4 & 60,9 \\ \text { Yes } & 139 & 80,6 & 52,5\end{array}$

Get encouragement from husband to HCT

$\begin{array}{llll}\text { No } & 72 & 81,9 & 68,1 \\ \text { Yes } & 135 & 77,8 & 48,9\end{array}$

Time you knew HIV status

Before being pregnant

$109 \quad 79,8 \quad 45,9$

While I was pregnant

$83 \quad 80,7 \quad 69,9$

At the time of delivery

After giving birth

$13 \quad 92,3 \quad 69,2$

$5 \quad 0,0 \quad 0,0$

Have you told your HIV status to anyone?

$\begin{array}{llll}\text { Yes } & 55 & 70,9 & 61,5 \\ \text { No } & 153 & 81,7 & 50,9\end{array}$

Know site that gives HCT

$\begin{array}{llll}\text { No } & 20 & 80,0 & 50,0 \\ \text { Yes } & 189 & 79,4 & 56,6\end{array}$

Who attended the birth of child?

$\begin{array}{llll}\text { Traditional birth attendant } & 28 & 32,1 & 25,0 \\ \text { Doctor } & 26 & 80,8 & 61,5 \\ \text { Nurse/Mid-wife/Other } & 155 & 87,7 & 60,7\end{array}$

SES quintile

$\begin{array}{llll}\text { 1st quintile(poorest) } & 47 & 68,1 & 48,9 \\ \text { 2nd quintile } & 59 & 78,0 & 59,3 \\ \text { 3rd quintile } & 56 & 82,1 & 55,4 \\ \text { 4th quintile } & 27 & 88,9 & 70,4 \\ \text { 5th quintile(richest) } & 21 & 85,7 & 42,9 \\ \text { Place of residence } & & & \\ \text { Urban } & 72 & 85,4 & 57,7 \\ \text { Rural } & 137 & 66,7 & 51,4\end{array}$


Table 1 Background individual and community-level characteristics of post-partum women who were attending health facility for the child immunization and mother and child PMTCT service in Tigray region Ethiopia (Continued)

\begin{tabular}{|c|c|c|c|}
\hline \multicolumn{4}{|l|}{ Proximity } \\
\hline$<1 \mathrm{~km}$ & 62 & 88,7 & 54,8 \\
\hline $1-5 \mathrm{kms}$ & 42 & 85,7 & 69,1 \\
\hline$>5 \mathrm{kms}$ & 37 & 59,5 & 48,6 \\
\hline \multicolumn{4}{|c|}{ Number of people per Nurse } \\
\hline$\leq 1500$ & 86 & 84,9 & 47,7 \\
\hline$>1500$ & 124 & 75,0 & 61,3 \\
\hline \multicolumn{4}{|c|}{ Number of people per health workers } \\
\hline$\leq 500$ & 71 & 85,9 & 47,9 \\
\hline$>500$ & 139 & 75,5 & 59,7 \\
\hline \multicolumn{4}{|c|}{ Number of people per health facility } \\
\hline$\leq 25000$ & 170 & 78,2 & 55,3 \\
\hline$>25000$ & 40 & 82,5 & 57,5 \\
\hline \multicolumn{4}{|c|}{ Number of people per laboratory technician } \\
\hline$\leq 3100$ & 112 & 85,7 & 56,2 \\
\hline$>3100$ & 98 & 71,4 & 55,1 \\
\hline \multicolumn{4}{|c|}{ Proportion of poorest and poor household } \\
\hline$<30 \%$ & 73 & 78,1 & 58,9 \\
\hline $30-60 \%$ & 78 & 75,6 & 57,7 \\
\hline$>60 \%$ & 59 & 84,8 & 49,2 \\
\hline \multicolumn{4}{|c|}{ Proportion of women with no education } \\
\hline$<30 \%$ & 104 & 77,9 & 54,8 \\
\hline $30-50 \%$ & 83 & 77,1 & 59,0 \\
\hline$>50 \%$ & 23 & 91,3 & 47,8 \\
\hline \multicolumn{4}{|c|}{ Ever HIV test kit run out of stock? } \\
\hline No & 40 & 67,5 & 40,0 \\
\hline Yes & 170 & 81,8 & 59,4 \\
\hline \multicolumn{4}{|c|}{ Ever ART run out of stock? } \\
\hline No & 145 & 77,9 & 55,2 \\
\hline Yes & 65 & 81,5 & 56,9 \\
\hline \multicolumn{4}{|c|}{ Test syphilis during pregnancy? } \\
\hline No & 21 & 85,7 & 66,7 \\
\hline Yes & 189 & 78,3 & 54,5 \\
\hline \multicolumn{4}{|c|}{ The number of HCT site in the district } \\
\hline$<3$ & 78 & 85,9 & 47,4 \\
\hline $3-5$ & 108 & 74,1 & 60,2 \\
\hline$>5$ & 24 & 79,2 & 62,5 \\
\hline \multicolumn{4}{|c|}{ The number of PMTCT sites in the district } \\
\hline None & 8 & 75,0 & 37,5 \\
\hline$\leq 2$ & 171 & 80,1 & 56,7 \\
\hline$>2$ & 31 & 74,2 & 54,8 \\
\hline
\end{tabular}

95\% CI 3.39,20.33) and child (OR = 3.11; 95\% CI 1.17,8.25), compared to who did not receive a CD4 count. Contrary to our expectation, planned pregnancy $(\mathrm{OR}=0.54 ; 95 \% \mathrm{CI}$ $0.28,1.05)$ and getting encouragement from husband to access $\mathrm{HCT}(\mathrm{OR}=0.42$; 95\% CI $0.21,0.83)$ decreased the chance of getting PMTCT services for a child. Per our expectation a mother coming from an urban area was 3.2 times $(\mathrm{OR}=3.19 ; 95 \%$ CI $1.46,6.97)$ more likely to receive PMTCT services compared to her rural counterparts. Proximity to health facility and laboratory technician workload were associated with getting PMTCT services for women (Table 2).

\section{Mother adjusted multilevel modeling result}

Multivariate multilevel modeling (adjusted) (Table 2) showed that, after controlling for the variables that were significant in bivariate multilevel modeling. A mother who was delivering at health facility had almost a 18 fold $(\mathrm{AOR}=18.21 ; 95 \% \mathrm{CI} 4.37,75.91)$ higher chance to receive PMTCT services than a mother who gave birth at home. More of the community level variables were significantly associated with mother getting PMTCT services than the child. A mother who was living within the $<1 \mathrm{~km}$ radius proximity to health facility had higher odds (AOR $=4.57 ; 1.21,17.34)$ of getting PMTCT services than a mother who was living within $>5 \mathrm{kms}$ radius. For every addition of one nurse per 1500 people, the likelihood of getting PMTCT services for a mother increases by 7.22 fold ( $\mathrm{AOR}=7.22$; 95\% CI 1.02,51.26), when other individual and community level factors were controlled simultaneously. In addition to this, adding one laboratory technician for every 3100 people, improves the odds of getting PMTCT services for a mother by 9.27 fold $(\mathrm{AOR}=9.27 ; 95 \%$ CI 1.55,55.24) (Table 2).

\section{Child adjusted multilevel modeling result}

The results in Table 2 showed that, a child born at a health facility had almost 7 times $(\mathrm{OR}=6.93 ; 95 \% \mathrm{CI}$ $2.27,21.14)$ and almost 5 times $(\mathrm{AOR}=4.77 ; 95 \% \mathrm{CI}$ $1.21,18.83$ ) higher chance to get PMTCT services compared to a child born at home, before and after controlling for other variables, respectively. A child born to a mother who had a CD4 count was 3.5 times $(\mathrm{AOR}=3.47 ; 95 \% \mathrm{CI}$ 1.05,11.43) more likely to get PMTCT services than the child born to a mother whose CD4 count was not done, controlling for the other variables. Another individual level factor significantly (though negatively) associated with child getting PMTCT service even after controlling for other variables was getting encouragement from husband to have HCT; a child born to a mother who got this encouragement was $63 \%$ less $(\mathrm{AOR}=0.37 ; 95 \% \mathrm{CI}$ $0.16,0.89)$ likely to receive PMTCT services than a child born to a mother who did not get the encouragement. Among the community level variables "ever HIV test kit 
Table 2 Results of the multilevel analysis of post-partum women who were attending health facility for the child immunization and mother and child PMTCT services in Tigray region Ethiopia

\begin{tabular}{|c|c|c|c|c|}
\hline \multirow[t]{2}{*}{ Variables } & \multicolumn{2}{|l|}{ PMTCT Mother } & \multicolumn{2}{|l|}{ PMTCT Child } \\
\hline & Crude OR(Cl) & Adjusted OR(Cl) & Crude $\mathrm{OR}(\mathrm{Cl})$ & Adjusted $\mathrm{OR}(\mathrm{Cl})$ \\
\hline \multicolumn{5}{|l|}{ Household size } \\
\hline$\leq 3$ & & & $2.85(1.088-7.456)$ & 3.03(0.963-9.508) \\
\hline$>3$ & & & 1 & 1 \\
\hline \multicolumn{5}{|l|}{ Where was the child born? } \\
\hline Home & 1 & 1 & 1 & 1 \\
\hline Health facility & 13.99(4.940-39.595) & 18.21(4.369-75.908) & $6.93(2.274-21.142$ & $4.77(1.209-18.834)$ \\
\hline \multicolumn{5}{|l|}{ Planned pregnancy } \\
\hline No & & & 1 & 1 \\
\hline Yes & & & $0.54(0.277-1.054)$ & $0.39(0.157-0.960)$ \\
\hline \multicolumn{5}{|l|}{ Have you had CD4 count? } \\
\hline Yes & $8.30(3.391-20.335)$ & & $3.11(1.170-8.250)$ & $3.47(1.052-11.431)$ \\
\hline No & 1 & & 1 & 1 \\
\hline \multicolumn{5}{|c|}{ Get encouragement from husband to HCT } \\
\hline No & & & 1 & 1 \\
\hline Yes & & & $0.42(0.210-0.834)$ & $0.37(0.156-0.892)$ \\
\hline \multicolumn{5}{|l|}{ Time you knew HIV status } \\
\hline Before being pregnant & 1 & & 1 & \\
\hline While I was pregnant & $1.06(0.514-2.192)$ & & $3.50(1.675-7.293)$ & \\
\hline At the time of delivery & $3.04(0.373-24.804)$ & & $3.68(0.904-14.993)$ & \\
\hline After giving birth & $0.00(0.000-8)$ & & $0.00(0.000-8)$ & \\
\hline \multicolumn{5}{|c|}{ Who attended the birth of child? } \\
\hline Traditional birth attendant & 1 & & 1 & \\
\hline Doctor & $9.06(2.471-33.233)$ & & 7.16(1.814-28.300) & \\
\hline Nurse/Mid-wife/Other & 15.55(5.718-42.308) & & $7.21(2.403-21.651)$ & \\
\hline \multicolumn{5}{|l|}{ Place of residence } \\
\hline Urban & $3.19(1.461-6.968)$ & & & \\
\hline Rural & 1 & & & \\
\hline \multicolumn{5}{|l|}{ Proximity } \\
\hline$<1 \mathrm{~km}$ & $5.36(1.923-14.921)$ & $4.57(1.206-17.345)$ & & \\
\hline $1-5 \mathrm{kms}$ & 4.09(1.382-12.109) & $2.36(0.666-8.390)$ & & \\
\hline$>5 \mathrm{kms}$ & 1 & 1 & & \\
\hline \multicolumn{5}{|l|}{ Number of people per Nurse } \\
\hline$\leq 1500$ & $1.89(0.894-3.991)$ & $7.22(1.016-51.265)$ & $0.58(0.287-1.176)$ & $0.41(0.175-0.976)$ \\
\hline$>1500$ & 1 & 1 & 1 & 1 \\
\hline \multicolumn{5}{|c|}{ Number of people per health workers } \\
\hline$\leq 500$ & $1.98(0.912-4.277)$ & & & \\
\hline$>500$ & 1 & & & \\
\hline \multicolumn{5}{|c|}{ Number of people per laboratory technician } \\
\hline$\leq 3100$ & $2.40(1.207-4.771)$ & $9.27(1.555-55.238)$ & & \\
\hline$>3100$ & 1 & 1 & & \\
\hline \multicolumn{5}{|c|}{ Ever HIV test kit run out of stock? } \\
\hline No & 1 & 1 & 1 & \\
\hline Yes & 2.38(0.948-5.974) & $3.48(0.813-14.920)$ & $2.83(1.062-7.524)$ & \\
\hline
\end{tabular}


run out of stock" was significantly associated with child getting PMTCT services, even though, the significance disappeared when it was adjusted for the other variables. Nurse work load was the only community level variable that was significantly associated with child getting PMTCT service when other variables were controlled; but against our expectation adding one nurse for every 1500 people decrease the likelihood of child getting PMTCT service by $59 \%(\mathrm{AOR}=0.41 ; 95 \% \mathrm{CI} 0.18,0.98)$.

\section{Random effect result}

The community level VPC was $4.6 \%$, showing there was a slight difference in getting PMTCT services for mothers at the community level; however, this slight difference disappeared $(\mathrm{VPC}=0.6 \%)$ when different variables were controlled for. This confirmed minimal difference in getting PMTCT services at the community level (Table 3).

The child multivariate multilevel modeling showed that the community level VPC was $12.5 \%$ for the null model. When the model is controlled for the variables that were significant in crude multilevel modeling, the VPC increased to $27.2 \%$ (Table 4).

\section{Discussion}

The implementation of strategies to eliminate MTCT remains a major challenge in developing countries [36-39]. To our knowledge, this study constitutes the first multilevel analysis to explore factors associated with receiving PMTCT services in Ethiopia. The proportion of mothers getting PMTCT services (79\%) in our study were comparatively higher than the findings reported from Tigray Bureau of Health in 2010 (47.9\%) [35], Addis Ababa in 2009 (53.7\%) [40], Oromia in 2008 (35\%) [19], Ethiopia in 2009 (18\%) [18], the Eastern and Southern Africa region in 2011 (64\%) [37], and India (60\%) [39]. The proportion of children getting PMTCT services (55.7\%) was higher than reported from Tigray Bureau of Health in 2010 (26.9\%) [35], Addis Ababa in 2009 (40.7\%) [38]. Oromia in 2008 (29\%) [19], Ethiopia in 2009 (15\%) [18].
This might be due to the fact that the study was limited to health facility attending mothers and ignored the mothers who did not patronize the child immunization in the participating facilities.

This study revealed that the mothers delivering at a health facility and children born at a health facility have increased chances of getting PMTCT services in Ethiopia. This finding is consistent with the studies conducted in Ethiopia [41], and elsewhere [42,43]. PMTCT services in Ethiopia are accessed only in health facilities. Children born elsewhere have less chance to get PMTCT services if their parents did not bring them to a health facility. This underlines the importance of health facility based delivery in Ethiopia to decrease significantly MTCT and to achieve MDG goal 4. However, $16 \%$ mothers and almost $40 \%$ children did not get PMTCT services at the delivery in spite of having given birth at a health facility. This puts the mothers and children at increased risk of MTCT, and implies a health system failure; especially of the birth attendant in the health facility. Therefore, continued training on the PMTCT guidelines for birth attendants and improved supervision may reduce the number of missed opportunities. At the individual level, mothers having a CD4 count were more likely to receive PMTCT services as well as their children, but when adjusted for the other variables the significant association for the mother disappeared. In contrast to our expectation getting encouragement from husband to HCT appeared to decrease the probability of child getting PMTCT service. The counterintuitive results here, as well as on the negative impact of improved staffing levels on the likelihood of a child receiving PMTCT, need further examination. We suggest that they might reflect the weak integration of post-delivery aspects of PMTCT into both programmes and parents' expectations, if supportive husbands and better PMTCT staffing also indicate a stronger focus on pregnant women rather than on the HIV risk of children. The data in our study cannot answer - but do raise - possible important questions for further research.

Table 3 Random effect results of the post-partum women who were attending health facility for the child immunization and mother PMTCT services in Tigray region Ethiopia

\begin{tabular}{lllll}
\hline Random effect & Model 1 & Model 2 & Model 3 & Model 4 \\
\hline Intercept & $1.37(0.203)$ & $-1.73(1.518)$ & $-0.50(1.554)$ & $-0.94(1.124)$ \\
Community-level variance (SE) & $0.16(0.370)$ & $0.07(0.741)$ & $0.00(0.000)$ & $0.02(0.789)$ \\
VPC (\%) & 4.6 & 2.1 & 0.0 & 0.6 \\
Proportional change in community level variance & Reference & 56.2 & 100 & 87.5 \\
Model fit statistics & & & 115.3768 & 98.0654 \\
DIC(-2log likelihood) & 215.3306 & 139.0594 & &
\end{tabular}

Model 1 Null model.

Model 2 Only individual level explanatory variables included in the model.

Model 3 Only community level explanatory variables included in the model.

Model 4 Full model. 
Table 4 Random effect results of the post-partum women who were attending health facility for the child immunization and child PMTCT services in Tigray region Ethiopia

\begin{tabular}{lllll}
\hline Random effect & Model 1 & Model 2 & Model 3 & Model 4 \\
\hline Intercept & $0.27(0.190)$ & $-6.14(2.325)$ & $0.99(1.345)$ & $-2.32(1.242)$ \\
Community-level variance (SE) & $0.47(0.401)^{*}$ & $0.70(0.650)^{*}$ & $0.27(0.379)$ & $1.23(1.086)^{*}$ \\
VPC (\%) & 12.5 & 17.5 & 7.6 & 27.2 \\
Proportional change in community level variance & Reference & 48.9 & 42.6 & 61.8 \\
Model fit statistics & & & 178.6708 & 116.3478 \\
DIC(-2log likelihood) & 285.2762 & 165.2646 & & \\
\hline
\end{tabular}

*significant at $p$-value $<0.05$

Model 1 Null model.

Model 2 Only individual level explanatory variables included in the model.

Model 3 Only community level explanatory variables included in the model.

Model 4 Full model.

At the contextual level, the current study found facility proximity, nurse work load, and laboratory technician work load were significantly associated with mothers getting PMTCT services; even when adjusted for the other variables. Our study finding showed that when the health facility was nearer to the place where the mother lives, the probability of getting PMTCT services increase dramatically. In addition to this our study revealed that, increasing the number of nurses and laboratory technicians to a given community increases significantly the likelihood of mothers getting PMTCT services. This finding is consistent with the other studies conducted previously $[9,16-21]$. This might be due to proximity and large number of health workers; they know easily the status of the mother and are able give all the available services, including PMTCT when she come to deliver. However, for the children all except nurse load community level variables were not significantly associated in getting PMTCT services.

The current study showed that random effects of the contextual level were significant in mothers receiving PMTCT services. The finding implies that unmeasured factors at the contextual level determine receiving PMTCT services of mothers beyond individual level was $4.6 \%$ in null model and $0.6 \%$ in full model. This shows that the contextual level effect was very small and a mother receiving PMTCT services were mostly dictated by the individual level variables. Although in children, the random effects showed great difference at the contextual level, it did not reach statistical significance.

The current study has several limitations. Causality could not be inferred, as it has a cross-sectional design. Due to the sensitive nature and interest to get enough number of participant on the study, the sample of HIV infected mothers were not selected randomly. The study was health facility based, therefore mothers who did not come for the child immunization to get services in the participating health facilities were excluded. Another limitation might be a recall bias, as the mothers were interviewed about events that occurred many months back. Furthermore internal validity could be affected by the different data collectors. To minimize this risk, data collectors were all midwifes well acquainted with the issue under study and were given training. Even though the purposes of the study have been explained to reduce social desirability bias, it might have been introduced due to the self-report. Additionally, defining districts based on the administratively defined boundaries might misclassify individuals into an inappropriate social and cultural boundary. This could generate information biases and reduce the validity of analysis.

\section{Conclusions}

This study sheds light on the factors that determine mother and child receiving PMTCT services, operating at individual and community levels. The multilevel modeling approach allows identifying several factors at individual (for instance, place of delivery, having CD4 count) and community level (for example proximity, nurse work load) hindering the application of PMTCT services simultaneously. This may allow differentiating and accentuating approaches for different settings in Ethiopia. The government should therefore focus on increasing health facility delivery and HCT coverage to increase mother-child pairs who are getting PMTCT service. Reducing the distance to health facility, increasing the number of nurses and laboratory technicians are also important variables to be considered by the government.

\section{Competing interests}

The authors declare that they have no competing interests.

\section{Authors' contributions}

WL, DJ, SC have made substantial contributions to conception, design, analysis and interpretation of data; WL, DJ, SC, CZ, MT involved in drafting the manuscript, revising it critically for important intellectual content; and al have given final approval of the version to be published. 


\section{Acknowledgments}

This study was funded by the Vlaamse Interuniversitaite Road. DJ and WL are also supported by the South African National Research Foundation.

\section{Author details}

${ }^{1}$ School of Public Health, University of the Western Cape, Cape town, South Africa. ${ }^{2}$ College of Health Science, Mekele University, Mekele, Ethiopia. ${ }^{3}$ Department of Internal Medicine, Infectious Diseases and Psychosomatic Medicine University Hospital Ghent, Ghent, Belgium. ${ }^{4}$ Department of Obstetrics and Gynecology, University Hospital Ghent and International Centre for Reproductive Health, Ghent University, Ghent, Belgium.

\section{Received: 6 August 2013 Accepted: 8 April 2014}

Published: 23 April 2014

\section{References}

1. UNAIDS: UNAIDS report on the global AIDS epidemic 2010. Geneva: Joint United Nations programme on HIV/AIDS (UNAIDS); 2010.

2. UNAIDS: UNAIDS report on the global AIDS epidemic 2012. Geneva: Joint United Nations programme on HIV/AIDS (UNAIDS); 2012.

3. Cooper ER, Charurat M, Mofenson L, Hanson IC, Pitt J, Diaz C, Hayani K, Handelsman E, Smeriglio V, Hoff R, Blattner W, Women and Infants' Transmission Study Group: Combination antiretroviral strategies for the treatment of pregnant HIV-1-infected women and prevention of perinatal HIV-1 transmission. J Acquir Immune Defic Syndr 2002, 29:484-494

4. UNAIDS: Prevention of HIV transmission from mother to child. Geneva, Switzerland: Strategic options; 1999

5. WHO: HIV transmission through breast feeding. A review of available evidence Geneva, Switzerland 2004; 2004

6. Goga AE, Dinh TH, Jackson DJ, for the SAPMTCTE study group: Evaluation of the effectiveness of the national prevention of mother-to-child transmission (PMTCT) programme measured at Six weeks postpartum in South Africa, 2010. South African medical research council, national department of health of South Africa and PEPFAR/US centers for disease control and prevention; 2012. ISBN: 978-1-920014-87-2.

7. Family Health International (FHI): Preventing mother-to-child transmission of HIV: a strategic framework; 2004

8. Grimwood A, Fatti G, Mothibi E, Eley B, Jackson D: Progress of preventing mother-to-child transmission of HIV at primary healthcare facilities and district hospitals in three South African provinces. S Afr Med J 2012, 102(2):81-83.

9. Siegfried $N$, van der Merwe $L$, Brocklehurst $P$, Sint $\Pi$ : Antiretrovirals for reducing the risk of mother-to-child transmission of HIV infection. Cochrane Database Syst Rev 2011, (7):CD003510. doi:10.1002/14651858. CD003510.pub3.

10. Paintsil E, Andiman WA: Update on successes and challenges regarding mother-to-child transmission of HIV. Curr Opin Pediatr 2009, 21(1):94-101.

11. Federal Ministry of Health-Federal HIV/AIDSV Prevention and Control Office (FHAPCO): Single point HIV prevalence estimate. Addis Ababa, Ethiopia: FHAPCO; 2010.

12. CSA, ORC Macro: Ethiopia demographic and health survey. Addis Ababa Ethiopia and Calverton, Maryland, USA: CSA and ORC Macro; 2006.

13. Save the Children UK: Child situation analysis for Ethiopia. Addis Ababa, Ethiopia: Save the Children UK, London; 2004.

14. Temmerman M, Quaghebeur A, Mwanyumba F, Mandaliya K: Mother-tochild HIV transmission in resource poor settings: how to improve coverage? AIDS 2003, 17:1239-1242.

15. Médecins sans Frontières: MSF and HIV/AIDS: expanding treatment, facing New challenges. Available from http://www.msf.org/article/msf-and-hivaidsexpanding-treatment-facing-new-challenges

16. Sprague C: A capabilities approach to understanding HIV prevention and treatment for pregnant women and children in South Africa. South Africa: Doctoral thesis. University of the WitWatersrand; 2009.

17. Delva W, Draper B, Temmerman M: Implementation of single-dose nevirapine for prevention of MTCT of HIV-lessons from Cape Town. SAMJ 2006, 96(8):706. 708-9.

18. Mirkuzie AM, Hinderaker SG, Mørkve O: Promising outcomes of a national programme for the prevention of mother-to-child HIV transmission in Addis Ababa: a retrospective study. BMC Health Serv Res 2010, 10:267.

19. Balcha TT, Lecerof SS, Jeppsson AR: Strategic challenges of PMTCT program implementation in Ethiopia. JIAPAC 2011, 10:187.

20. Nguyen $T$, Oosterhoff $P, \operatorname{Ngoc} Y$, Wright $P$, Hardon A: Barriers to access prevention of mother-to-child transmission for HIV positive women in a well-resourced setting in Nietnam. AIDS Res Ther 2008, 5:7.

21. O'Gorman D, Nyirenda L, Theobald S: Prevention of mother-to-child transmission of HIV infection: views and perceptions about swallowing nevirapine in rural Lilongwe, Malawi. BMC Public Health 2010, 10:354.

22. Jackson D, Chopra M, Doherty T, Colvin M, Levin J, for the Good start study group: Operational effectiveness and 36 week HIV-free survivalin the South African programme to prevent mother-to-child transmission of HIV-1. AIDS 2007, 21:509-516.

23. Diez-Roux AV: Multilevel analysis in Public Health research. Annu Rev Public Health 2000, 21:171-192.

24. Goldstein H: Multilevel statistical models. 3rd edition. Oxford: Oxford University press, Kendall's Library of Statistics; 2003

25. Hox J: Multilevel analysis, techniques and applications. Mahwah, New Jersey: Lawrence Erlbaum Associates; 2002

26. Diez-Roux AV: Bringing context back into epidemiology: variables and fallacies in multi-level analysis. Am J Public Health 1998, 88:216-222.

27. Pickett KE, Pearl M: Multilevel analyses of neighbourhood socioeconomic context and health outcomes: a critical review. J Epidemiol Community Health 2001, 55(2):111-122

28. Belsky J, Jaffee $\mathrm{S}$ : The multiple determinants of parenting. In Developmental psychopathology. 2nd edition. Edited by Cicchetti D, Cohen D. New York, NY: Wiley; 2005.

29. Bronfenbrenner U: Ecological models of human development. In International encyclopedia of education, Volume 3. 2nd edition. Oxford: Elsevier; 1994

30. Creek T, Ntumy R, Mazhani L, Moore J, Smith M, Han G, Shaffer N, Kilmarx PH: Factors associated with low early uptake of a national program to prevent mother to child transmission of HIV (PMTCT): results of a survey of mothers and providers, Botswana, 2003. AIDS Behav 2009, 13(2):356-364.

31. Prinstein MJ, Brechwald WA, Cohen GL: Susceptibility to peer influence: using a performance-based measure to identify adolescent males at heightened risk for deviant peer socialization. Dev Psychol 2011, 47:1167-1172.

32. Subramanian SV, Smith GD: Patterns, distribution, and determinants of under and over nutrition: a population based study of women in India. Am J Clin Nutr 2006, 84(3):633-640.

33. Central Statistical Agency (CSA) [Ethiopia]: Statistical abstract of Ethiopia. Addis Ababa, Ethiopia: Central Statistical Agency; 2009.

34. CSA: The 2007 population and housing census of Ethiopia. Statistical summary report at national level. Addis Ababa, Ethiopia: Central Statistical Agency; 2008.

35. Tigray region: Health Bureau anual report. Mekele, Ethiopia: Tigray region Health Bureau; 2010.

36. Darak S, Panditrao M, Parchure R, Kulkarni V, Kulkarni S, Janseen F: Systematic review of public health research on prevention of mother-to-child transmission of HIV in India with focus on provision and utilization of cascade of PMTCT services. BMC Public Health 2012, 12:320.

37. THE INTERAGENCY TASK TEAM: Preventing mother-to-child transmission (PMTCT) of HIV. Factsheets on the status of national PMTCT responses in the most affected countries, 2010. Available at http://www.emtct-iatt.org/priority-countries/.

38. GLOBAL HIV/AIDS RESPONSE: Epidemic update and health sector response progress towards Universal Access; 2012. Progress Report 2011 (WHO, UNAIDS, UNICEF).

39. UNGASS: India: country progress report NACO, Ministry of Health and Family Welfare. Government of India: UNGASS India; 2010.

40. Mirkuzie AM, Hinderaker SG, Sisay MM, Moland KM, Mørkve O: Current status of medication adherence and infant follow up in the prevention of mother to child transmission programme in Addis Ababa: a cohort study. J Int AIDS SOC 2011, 14:50.

41. Kuonza L, Tshuma CD, Shambira GN, Tshimanga M: Non-adherence to the single dose nevirapine regimen for the prevention of mother-to-child transmission of HIV in Bindura town, Zimbabwe: a cross-sectional analytic study. BMC Public Health 2010, 10:218 
42. Albrecht S, Semrau K, Kasonde P, Sinkala M, Kankasa C, Vwalika C, Aldrovandi GM, Thea DM, Kuhn L: Predictors of nonadherence to singledose nevirapine therapy for the prevention of mother-to-child HIV transmission. J Acquir Immune Defic Syndr 2006, 41(1):114-118.

43. Ekama SO, Herbertson EC, Addeh EJ, Gab-Okafor CV, Onwujekwe DI, Tayo F, Ezechi OC: Pattern and determinants of Antiretroviral drug adherence among Nigerian pregnant women. Hindawi Publishing Corporation. J Pregnancy 2012, 2012:1-6. Article ID 851810.

doi:10.1186/1472-6963-14-181

Cite this article as: Lerebo et al: Identifying factors associated with the uptake of prevention of mother to child HIV transmission programme in Tigray region, Ethiopia: a multilevel modeling approach. BMC Health Services Research 2014 14:181.

\section{Submit your next manuscript to BioMed Central and take full advantage of:}

- Convenient online submission

- Thorough peer review

- No space constraints or color figure charges

- Immediate publication on acceptance

- Inclusion in PubMed, CAS, Scopus and Google Scholar

- Research which is freely available for redistribution 